\title{
An annual cycle in the ventilatory capacity of men with pneumoconiosis and of normal subjects
}

\author{
C. B. MCKERROW AND C. E. ROSSITER
}

From the Pneumoconiosis Research Unit, Llandough Hospital, Penarth, Glamorgan

\begin{abstract}
The forced expiratory volume over 0.75 second (F.E.V.$_{0 \cdot 75}$ ) was measured monthly for 3 years in 28 working ex-miners with pneumoconiosis and for one year in 17 normal laboratory workers. A significant annual cyclical variation of 0.044 litre amplitude was found in the ex-miners, with minimum and maximum values on 2 February and 3 August respectively. In the normal subjects the amplitude of the change was about $0 \cdot 10$ litre. An attempt was made to relate the changes in ventilatory capacity in the ex-miners to those in environmental temperature, relative and absolute humidity, and barometric pressure. Dry-bulb temperature showed a cyclical pattern in phase with that of ventilatory capacity, but there was no strong correlation between the deviations from these cyclical components, which would have been desirable to support a causal relation between change of temperature and of ventilatory capacity. There was no definite evidence of a relationship between any other of the environmental parameters and ventilatory capacity. Fourteen of the ex-miners had purulent sputum at intervals but remained at work. Immediately after these attacks the ventilatory capacity was not lower than before, but those having attacks showed a greater annual decline in their F.E.V $\cdot_{0 \cdot 75}$. We think that the cyclical variation in ventilatory capacity is not directly caused by the environmental conditions measured, or by sputum purulence, but could represent an intrinsic biological rhythm which is perhaps modified by the environmental temperature.
\end{abstract}

Seasonal variation in both morbidity and mortality from respiratory disease is well known (Farr, 1885 ; Scottish Home and Health Department, 1963; Holland and Spicer, 1967). It has been established, too, that the ventilatory capacity is lower in subjects with chronic non-specific lung disease or with complicated pneumoconiosis than in comparable normal subjects (Gilson and HughJones, 1955 ; Higgins and Cochrane, 1961 ; Rogan, Ashford, Chapman, Duffield, Fay, and Rae, 1961 ; Fairbairn, Fletcher, Tinker, and Wood, 1962), but comparatively little is known of the way in which it comes to be impaired or of the possible presence of a cyclical variation in its value corresponding to seasonal morbidity, for most studies have been made at one point in time. Morgan, Pasqual, and Ashford (1964) found a small fall in ventilatory capacity in winter among working coal miners, and this seasonal variation was larger in those with respiratory symptoms and in older people. Several authors have noted a fall in ventilatory capacity or a rise in airways resistance in subjects with chronic respiratory diseases breathing air at $-20^{\circ} \mathrm{C}$. or below (Wells, Walker, and Hickler, 1960 ; Millar, Nairn, Unkles, and McNeill, 1965).

The present paper discusses part of a prospec울 tive study over three years of ex-miners with. pneumoconiosis working in a light engineering factory and provides evidence on seasonal variations in the ventilatory capacity.

The ventilatory capacity was measured approxi mately monthly in 28 subjects and we attempteces. to correlate the changes with atmospheric condio tions and mild chest infections causing a change in sputum appearance. A subsidiary investigatio was made over one year on a group of normał subjects.

\section{METHODS}

\section{THE SUBJECTS}

Men with pneumoconiosis In 1949 the Austin Motog Company set up a small factory 10 miles north of Cardiff to employ ex-miners with pneumoconiosis in light engineering and upholstery. The average number of men employed during the period of study was 2298 all had been certified under the National Insurance 
(Industrial Injuries) Act as having pneumoconiosis, but their disability varied widely.

The investigation was made on a volunteer sample, as was inevitable in a long-term prospective study. The objects were explained to a full meeting of dayshift men, emphasizing our interest in the causes of changes in their breathing. Eighty-three men volunteered in the first year, and the monthly observations began in October 1957 on 26 of them, who claimed that their breathing was affected by changes in the weather. This was about the largest number that could be seen so often without causing interference with the work of the factory. By the following October three men had had long periods of sickness absence and one had been transferred to night work, and it was clear that the size of the group must be increased to compensate for future wastage. Ten further subjects from the volunteer sample who had already been seen three times in the course of another investigation in the factory were added, and observations on this augmented group were continued for a further two years.

After the conclusion of the survey the attendance records of all the subjects were examined and a formula for scoring absence was devised to select those men who had been present on at least half the possible occasions and who had had the lowest number of long periods of absence:

$$
\text { Absence score }=\frac{1}{2} \mathrm{n}(\mathrm{n}+1)
$$

where $n$ is the number of consecutive tests missed in each period of absence summed over all the periods of absence.

The group finally selected comprised 19 of the men who had started in the first year and nine of those who had been added. The absence scores of those selected ranged from 0 to 138 , with a mean of $36 \cdot 5$. The proportion of missed tests in the selected subjects was $17 \%$; the statistical technique to allow for these is discussed below. Obviously, the selection method does not give a sample representative of the factory, and it might be that, by concentrating observations on those who claimed a weather effect, the seasonal changes found in the ventilatory capacity were higher than in the whole group of volunteers, but evidence from another study suggests that those who claim to be sensitive to weather have no greater seasonal changes in ventilatory capacity than those who do not. Again the selection of those with the lowest absence scores could produce a bias if their pattern of performance were markedly different from those with a poor attendance. A subsidiary investigation showed that those with an attendance rate of $80 \%$ or over had a slightly lower annual decline in ventilatory capacity than those with poorer attendance, but the difference was small.

The average age of the selected subjects was 54.7 years, with a range of 37 to 66 years. Nineteen of them regularly coughed up sputum on rising; 18 had complicated and the remaining 10 simple pneumoconiosis.
Normal subjects Twenty-one members of the staff of the Research Unit volunteered to do the ventilatory capacity test monthly for the second year of the study. All were in good health and had normal chest radiographs. Four failed to complete the tests for reasons unconnected with any chest illness and were omitted from the analysis. Of the remaining 17 subjects, eight were women, and the average age of the group at the start of the observations was $33 \cdot 5$ years (range 18-47). The proportion of missed tests was $8.6 \%$ and no subject had more than two consecutive months of absence.

VENTILATORY CAPACITY MEASUREMENT The forced expiratory volume over 0.75 second (F.E.V.0.75) was measured using a spirometer with an electronic timer (McKerrow, McDermott, and Gilson, 1960). The mean of three blows after two practice ones was taken and corrected to B.T.P.S. These values can be converted approximately to F.E.V.1.0 units by taking $108 \%$ of the F.E.V. 0.75 and adding 0.091 . to it.

In a prospective study serious error can be introduced by minor variations in technique or by small changes in the calibration of the instrument, so all F.E.V. measurements were made by one observer (C. B. McK.), and the spirometer was tested by the calibration device at least hourly during use. The extremes of calibration readings ranged from 3.05 1 . to 3.191 ., due probably to fluctuations in the voltage of the mains supply. The possible influence of this on the results was determined by a subsidiary experiment on 22 of the subjects in which two sets of ventilatory capacity figures were obtained simultaneously with the timers adjusted to give these two calibration figures. The difference in recorded ventilatory capacity was only $0.6 \%$. This relative insensitivity of the results to changes in the time interval reflects the comparatively low flow rate of the expired air after 0.75 second. The influence of change in the temperature of the spirometer water seal is discussed in the results section. The tests were done between $10.00 \mathrm{a} . \mathrm{m}$. and noon and each subject was seen at about the same time on each occasion.

ENVIRONMENTAL MEASUREMENTS The ventilatory capacity was measured in the factory's sick quarters within the main building, and the temperature of this room as well as that of the factory was recorded during the tests, although that of the latter was liable to rather large short-term fluctuations when doors were opened to accept or discharge materials.

We also had measurements of ambient temperatures, humidity, and barometric pressure at 9.00 a.m. kindly supplied by the Cardiff Meteorological Office from a station 10 miles south of the factory. These were compared over the first winter with measurements made in a Stevenson screen set in the factory grounds and the two sites were found to agree closely. As the workers came to the factory from a radius of some five miles, it was impracticable to make a more accurate assessment of each individual's environment. 
A filter paper sample for atmospheric pollution measurements was also included in the Stevenson screen. The levels of smoke concentration in these samples were extremely low, averaging below $4 \mathrm{mg}$./ $100 \mathrm{~m}^{3}{ }^{3}$ with no cyclical pattern, and they were not included in the final analysis of the ventilatory capacity data. Rokaw and Massey (1962) failed to find a response in respiratory function even during major smog episodes in their group of 25 patients with chronic non-tuberculous respiratory disease.

SICKNESS ABSENCE The factory records provided the duration of absence, and its cause was ascertained from doctors' certificates, supported where necessary by direct questioning of the individual. It was likely that generalized illness tended to be interpreted on certificates as arising from the chest in this group, but this bias was reduced by questioning about dyspnoea, chest pain, and changes in sputum production.

SPUTUM On the day of each test the subjects brought a specimen of sputum coughed up on rising. This was classified by macroscopic inspection into purulent or non-purulent, purulent corresponding to grade P2 and above in the classification of Miller and Jones (1963). This examination was done during the afternoon of the day of collection and independently of knowledge of previous assessments or of the clinical and physiological state of the subject. One observer made all the assessments in the first year of the study, and a second one subsequently. We did not think it feasible to collect sputum over a fixed time in order to estimate the volume.

\section{RESULTS}

\section{MEN WITH PNEUMOCONIOSIS}

Cyclical changes in ventilatory capacity In this group of only 28 men with widely varying F.E..$_{\cdot 0 \cdot 75}$ values, individual absences may seriously bias the average ventilatory capacity for any particular month. To overcome this, a preliminary analysis was done providing estimates of all the missing readings in the survey. These estimates were made so that the residual sum of squares in an ordinary analysis of variance was minimized. The method provided a pattern of the average results and revealed that not only was there a downward linear trend in ventilatory capacity with time, but also a superimposed sine wave. This sine wave had a period of 372 days $(95 \%$ fiducial limits from 336 to 418 days), sufficiently close to one year for an annual period to be assumed in the subsequent analyses.

Having established the sinusoidal change with time, it was necessary to perform a full analysis considering the patterns of change within the individual subjects. This analysis made no assump- $\stackrel{\overrightarrow{\bar{N}}}{\stackrel{\vec{D}}{\vec{D}}}$ tions regarding the position of any sine wave present with respect to season but did make use of the assumption from the preliminary analysis that any sine wave had a period of one year. An $\stackrel{\mathbb{\Omega}}{2}$ advantage of this full analysis was that it did not $\stackrel{0}{\circ}$ have to estimate missing readings.

The method used was as follows. First a linear trend and sine wave were fitted to the data for $\vec{\omega}$ each man. Thus, for the 28 men there were 28 o sine waves corresponding to the 84 degrees of $\vec{x}$ freedom in line 4 of Table I. Secondly, an indivi- స్ dual trend and an average sine wave (the same for $\rightarrow$ all subjects) were fitted to each subject's data. The $\omega$ peak of this average sine wave was on 3 August and its trough on 2 February, and its amplitude $\frac{\circ}{3}$ peak to trough was 0.044 litre.

T A B L E I

STATISTICAL ANALYSIS OF THE F.E.V.0.75 OF THE 28 SUBJECTS OVER 3 YEARS

\begin{tabular}{|c|c|c|c|}
\hline & $\begin{array}{c}\text { Degrees of } \\
\text { Freedom }\end{array}$ & $\begin{array}{l}\text { Mean } \\
\text { Square }\end{array}$ & $\underset{\text { Ratio }}{\text { Variance }}$ \\
\hline $\begin{array}{l}\text { Individual linear } \\
\text { change } \ldots \\
\text { Average sine wave } \\
\text { Heterogeneity of indi- } \\
\text { vidual sine waves }\end{array}$ & $\begin{array}{r}28 \\
2 \\
54\end{array}$ & $\begin{array}{l}0.20568 \\
0.07745 \\
0.00982\end{array}$ & $\begin{array}{l}11.44(0.001 \gg P) \\
1.45(0.05>P>0.01)\end{array}$ \\
\hline $\begin{array}{l}\text { Total of individual } \\
\text { sine waves } \\
\text { Residual } \quad \ldots\end{array}$ & $\begin{array}{r}84 \\
728\end{array}$ & $\begin{array}{l}0.07671 \\
0.00677\end{array}$ & \\
\hline Total & 812 & 0.01400 & 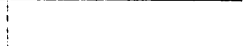 \\
\hline
\end{tabular}

The differences between this average sine wave and the individual sine waves indicated the heterogeneity of the latter, i.e., whether they differed in position or amplitude or in both. The analysis of variance showed that the average sine wave was very significant, but the 28 individual ones also differed significantly one from another, although this varianice was only $45 \%$ larger than the residual variance.

As would be expected, the linear trends for the $N$ individual subjects varied greatly, from a rise of $N$ 0.0751 . per year to a fall of 0.221 . per year. The $N$ relation of the individual linear trends to the type of pneumoconiosis and chest illness is considered later. The standard deviation of a single mean F.E.V. result on an individual was 0.0821 ., the coefficient of variation being $4.65 \%$.

Figures 1 and 2 , showing the performance of the whole group over the three years, were derived as follows. There is an expected value for the F.E.V. of each man on each of the 40 days, based on his individual trend and the average sine wave of the whole group. If he were absent, an estimate of what his F.E.V. would have been was made by 


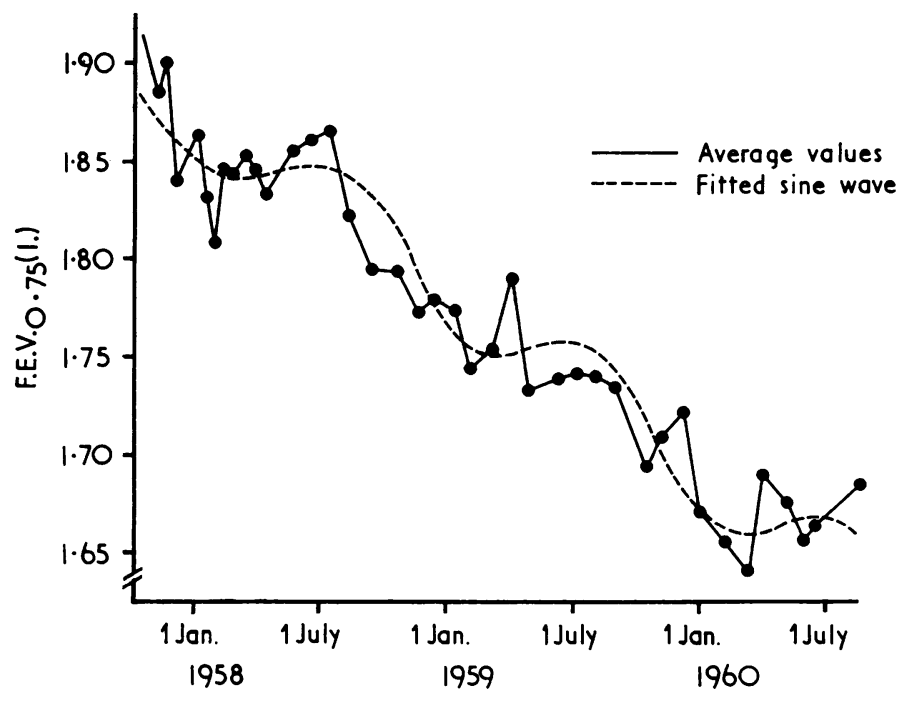

FIG. 1. The F.E.V..$_{0 \cdot 75}$ over three years in 28 subjects. The fitted sine wave is shown.

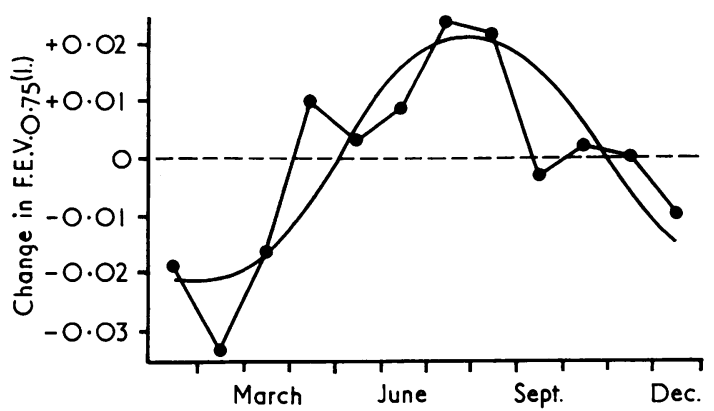

FIG. 2. Mean annual change in F.E.V. $\cdot_{0 \cdot 75}$ with the fitted sine wave. The linear decrement in ventilatory capacity has been removed.

adding or subtracting from his expected value the average amount by which all those who were present were greater or less than their expected values. Each point in Fig. 1 is the average of all these readings, whether actual or estimated in this way, and gives the pattern of variation unbiased by absences.

The cyclical variation over the year is shown in Fig. 2, in which the mean linear downward trend has been removed and the results for any particular month pooled so as to give an average yearly performance to demonstrate the strong seasonal change more clearly. The fitted sine wave with its amplitude of $0.044 \mathrm{l}$. is also shown.

The distribution throughout the year of the maximum points of the individuals' sine waves are shown as a histogram in Figure $3 \mathrm{~A}-\mathrm{C}$.
Although there is a highly significant cyclical variation in the F.E.V. of the group as a whole, with the peak in August, there is marked heterogeneity in the individual sine waves, and 11 of the subjects had their maximum points in the winter months. There is no obvious relationship between the position of the sine waves and the type of pneumoconiosis, the presence or absence of attacks of purulent sputum at work (see below), or whether the man has had two or more attacks of chest illness necessitating an absence of at least one week during the survey. Whatever may be the cause of this heterogeneity it does not appear to be due to these factors considered singly.

Relation to environmental measurements within the factory Changes in the immediate environment of the worker, whether on the factory floor or during the 2 to 5 minutes he usually waited in the sick quarters for his test, was an obvious possible cause of fluctuations in the ventilatory capacity.

The difficulty of establishing the exact temperature to which the subjects had been exposed in the factory has already been mentioned, and the figures should be taken as approximations. Any influence of the sick quarters' temperature might be mediated through changes in the temperature of the water seal of the spirometer, but as this was kept nearly constant by the addition of hot or cold water, it is most unlikely that it influenced the results.

Figure 4 shows the temperature of the factory and sick quarters on the days of the test. In 

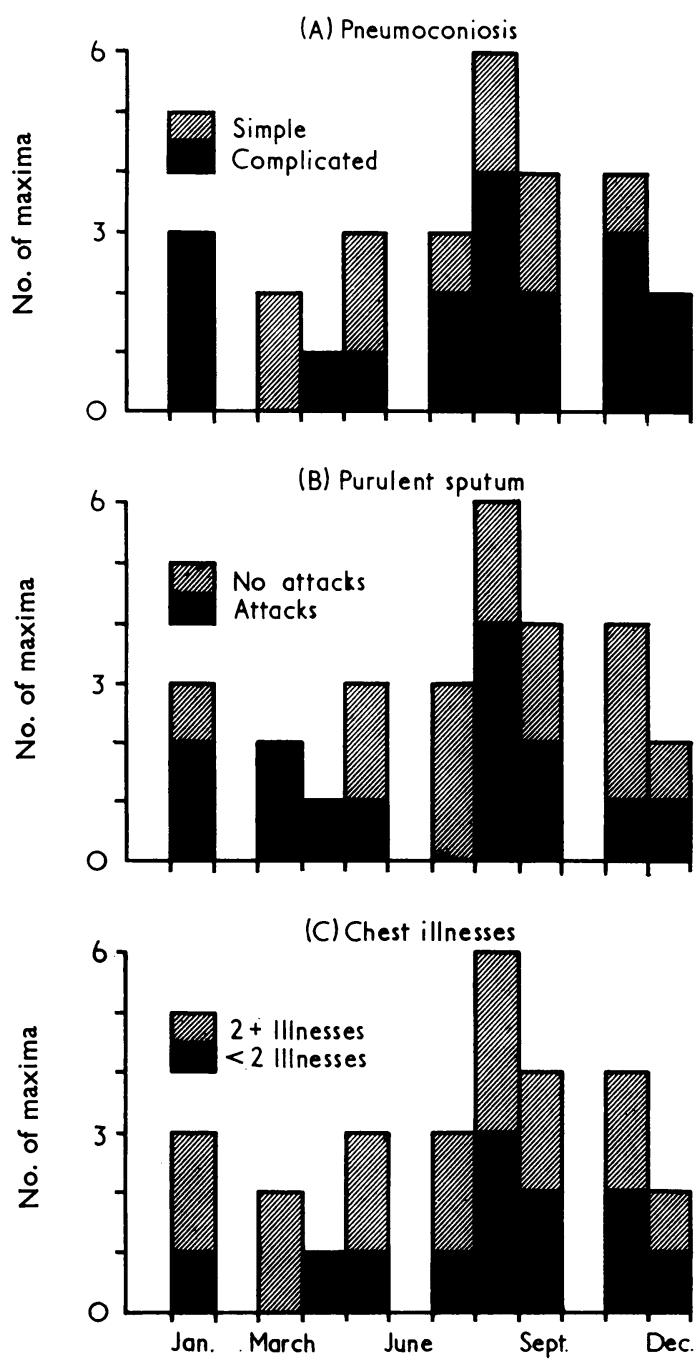

FIG. 3. Distribution of the maximum points of individuals' F.E. $V_{\cdot 0 \cdot 75}$ sine waves related to whether the individuals have (A) simple or complicated pneumoconiosis; (B) attacks of purulent sputum while remaining at work; (C) at least two chest illnesses during the survey, necessitating absence of at least a week.

neither was there a marked cyclical change with season, and there was no obvious relation with the change in ventilatory capacity (shown here and in Fig. 5 with the linear decrement removed). Also we found no relation between differences of factory and room temperatures and changes in the ventilatory capacity, suggesting that changes in the man's environment immediately before his test were not responsible for the fluctuations in the latter. Table II confirms that the correlation between ventilatory capacity and either factory or room temperature was low.

Relation to external environmental measurements The external temperature and humidity measurements contained cyclical components, which could be compared with that from the ventilatory capacity. The average seasonal change in dry-bulb temperature and relative and absolute humidity and their cyclical components are shown in Figure 5. No marked cyclical component was found in barometric pressure (Fig. 4).

Dry-bulb temperature and F.E.V. were almost exactly in phase, the former leading the latter by less than two days. Absolute humidity lagged by 19 days and the relative humidity by 120 days. The peak of the absolute humidity cycle and the trough of that of relative humidity were both
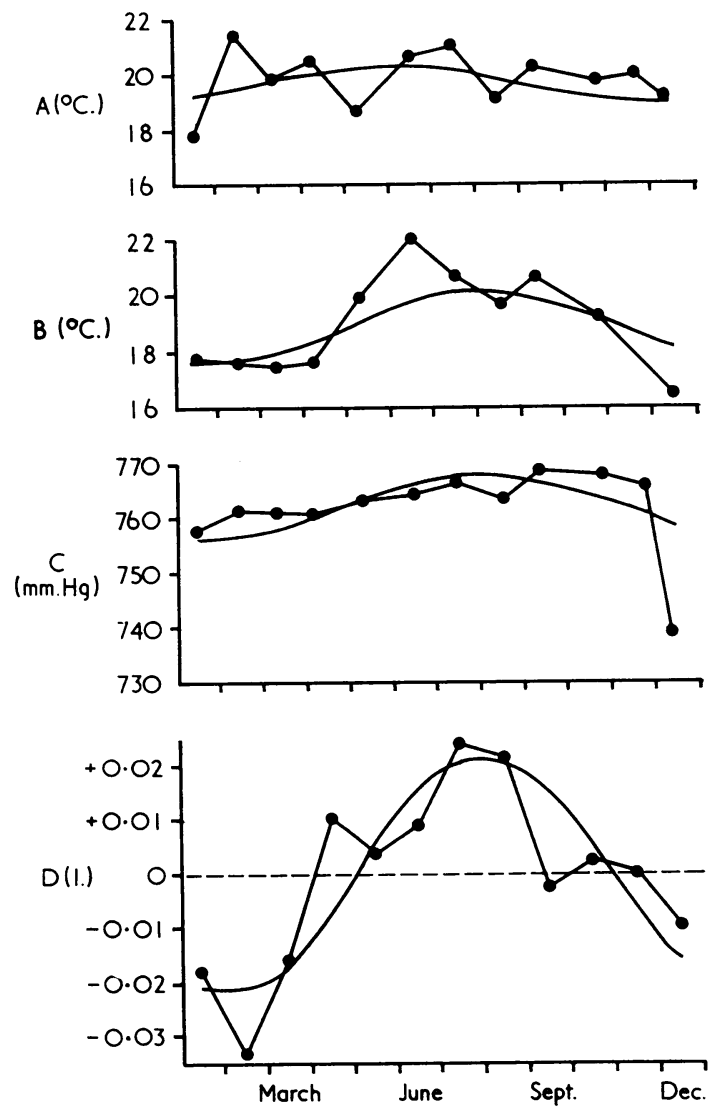

FIG. 4. Dry-bulb temperatures of the factory (A) and sick quarters (B), and barometric pressure (C), related to changes in the F.E.V. ${ }_{\cdot 0 \cdot 75}$ (D). 

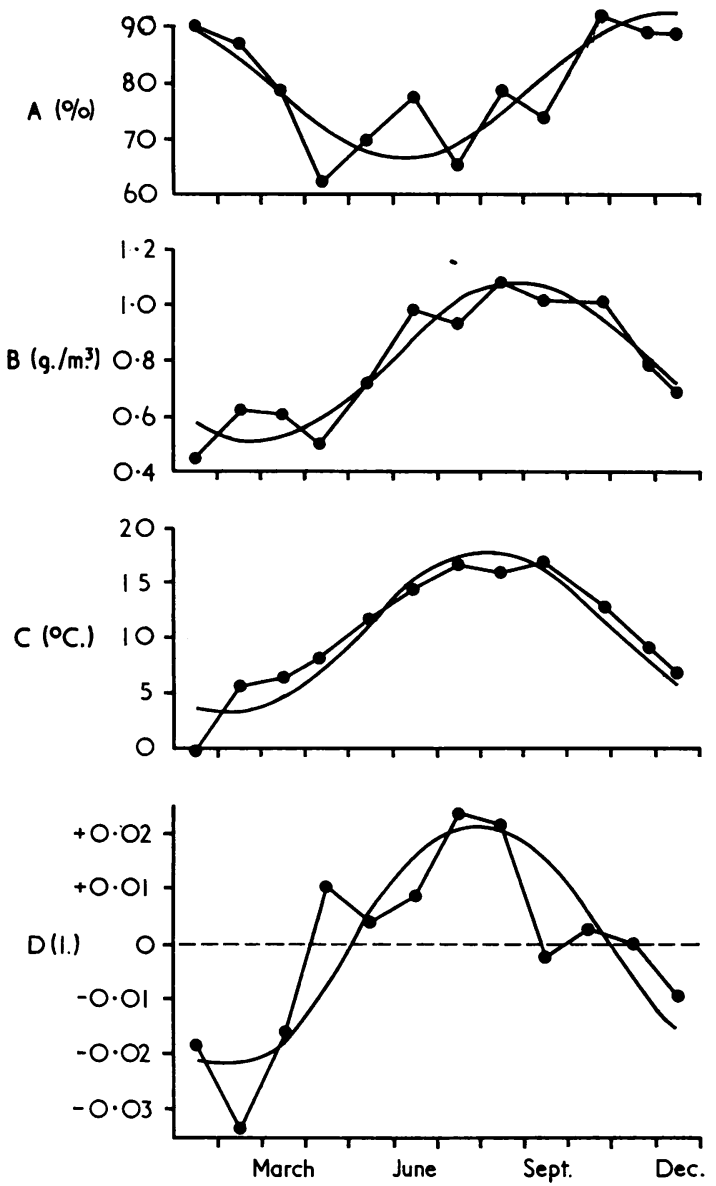

FIG. 5. Relative humidity (A), absolute humidity (B), and outside dry-bulb temperature $(\mathrm{C})$ related to changes in the F.E. $V_{\cdot 0 \cdot 75}$ (D).

highly significantly different from August 3 $(P<0.01$ and $P<0.001)$.

Hours of daylight was also considered as a possible factor related to ventilatory capacity, but the longest day preceded the peak of the F.E.V. cycle by 54 days and can probably be dismissed.

Thus of the possible factors influencing ventilatory capacity, the dry-bulb temperature was the most closely related in time. But a temporal correlation does not necessarily imply causation, even if one could assume that mechanisms of action involving a lag correlation were impossible. The conclusion that any single factor was causal would be strengthened if not only its cyclical component and that of the F.E.V. were in phase, or completely out of phase, but also if any deviations from these two sine waves were themselves highly correlated. Finally, the ratio of these deviations to the amplitude of the respective sine wave should be similar in both the factor and the F.E.V.

Table II presents the analysis of these interrelationships. Column 2 shows the correlation coefficient of the various factors with the F.E.V., and columns 3,4 , and 5 break the inter-relations down into the three parts discussed above. Column 3 shows the phase difference between the cyclical components, exactly in phase or out of phase being indicated by zero. The correlations between deviations from the sine waves of each factor and those of the F.E.V. are shown in column 4. Finally, for each factor the ratio of the size of the deviations from the cyclical component to its amplitude is compared in column 5 to the same ratio for the F.E.V.

Thus perfect agreement between a factor and the F.E.V. would be given by zero in column 3,

\section{T A B L E I I}

CORRELATIONS AND PHASE RELATIONS BETWEEN ENVIRONMENTAL FACTORS AND FORCED EXPIRATORY

\begin{tabular}{|c|c|c|c|c|}
\hline Factor & $\begin{array}{l}\text { Correlation } \\
\text { of Factor } \\
\text { with } \\
\text { F.E.V. }\end{array}$ & $\begin{array}{c}\text { Phase } \\
\text { Difference } \\
\text { between } \\
\text { Sine } \\
\text { Waves of } \\
\text { Factor } \\
\text { and } \\
\text { F.E.V. } \\
\text { (See } \\
\text { Note) }\end{array}$ & 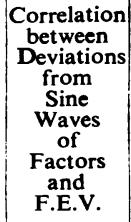 & $\begin{array}{c}\text { Ratio of } \\
\text { Deviations } \\
\text { about } \\
\text { Sine } \\
\text { Wave to } \\
\text { Amplitude } \\
\text { of Sine } \\
\text { Wave } \\
\text { (=1 for } \\
\text { F.E.V.) }\end{array}$ \\
\hline Factory temperature & +0.07 & -55 days & +0.00 & 29 \\
\hline Room temperature & +0.23 & -5 & -0.01 & $1 \cdot 5$ \\
\hline 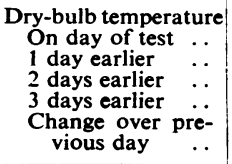 & $\begin{array}{l}+0.49 \\
+0.44 \\
+0.47 \\
+0.41 \\
-0.19\end{array}$ & $\begin{array}{r}-2 \\
-7 \\
-8 \\
-5 \\
+67^{1}\end{array}$ & $\begin{array}{l}+0.08 \\
-0.08 \\
-0.02 \\
-0.08 \\
-0.18\end{array}$ & $\begin{array}{l}0 \cdot 12 \\
0 \cdot 08 \\
0 \cdot 08 \\
0 \cdot 13 \\
49\end{array}$ \\
\hline $\begin{array}{c}\text { Absolute humidity } \\
\begin{array}{c}\text { On day of test } \\
1 \text { day earlier }\end{array} \\
2 \text { days earlier } \\
3 \text { days earlier } \\
\begin{array}{c}\text { Change over pre- } \\
\text { vious day }\end{array}\end{array}$ & $\begin{array}{l}+0.27 \\
+0.33 \\
+0.46 \\
+0.36 \\
-0.07\end{array}$ & $\begin{array}{r}+19 \\
+17 \\
+2 \\
+6 \\
+30\end{array}$ & $\begin{array}{l}-0.19 \\
-0.04 \\
+0.09 \\
+0.01 \\
-0.18\end{array}$ & $\begin{array}{l}0 \cdot 36 \\
0 \cdot 48 \\
0 \cdot 31 \\
0 \cdot 32 \\
19\end{array}$ \\
\hline 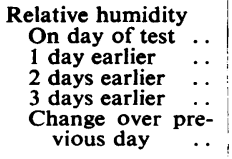 & $\begin{array}{l}-0.37 \\
-0.24 \\
-0.11 \\
-0.09 \\
+0.14\end{array}$ & $\begin{array}{r}-63^{1} \\
-48^{1} \\
-34^{1} \\
-64^{1} \\
0^{1}\end{array}$ & $\begin{array}{l}-0.27 \\
-0.00 \\
+0.13 \\
-0.03 \\
+0.31\end{array}$ & $\begin{array}{c}50 \\
1 \cdot 4 \\
2 \cdot 6 \\
44 \\
8 \cdot 2\end{array}$ \\
\hline 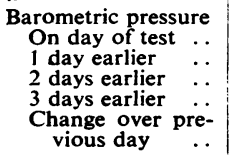 & $\begin{array}{l}+0.14 \\
-0.02 \\
+0.04 \\
+0.11 \\
-0.29\end{array}$ & $\begin{array}{l}-11 \\
-25 \\
-27 \\
-24 \\
+62^{1}\end{array}$ & $\begin{array}{l}-0.05 \\
-0.24 \\
-0.16 \\
-0.07 \\
-0.29\end{array}$ & $\begin{array}{l}2 \cdot 9 \\
3 \cdot 1 \\
3 \cdot 2 \\
4 \cdot 2\end{array}$ \\
\hline
\end{tabular}

Note: -55 days means F.E.V. sine wave lagged the factor sine wave by 55 days.

${ }^{1}$ Sine waves out of phase. 
1 in column 4 (or -1 if the relationship were out of phase), and 1 in column 5 .

The various factors are considered not only on the day of the test but also up to three days earlier in case the environment in the recent past might have influenced the ventilatory capacity. In addition we considered the possibility that a change in one of the factors from the previous day might be important. Examination of this table shows that none of the factors satisfies all three criteria. The only one that apparently satisfies two of them is change in relative humidity, but as this is out of phase we would have expected a negative correlation between the residuals, not the positive one observed.

Relation to changes in the sputum Of the 28 subjects, 14 on a total of 31 occasions produced purulent sputum specimens, as defined, but remained at work, so that it was possible to measure the acute effects on the ventilatory capacity. But allowances had to be made for the expected fall in ventilatory capacity due to time alone. These were calculated from the annual linear change of ventilatory capacity in each subject and applied to the F.E.V. during and after the attack of purulence.

Table III gives the mean ventilatory capacity on the three occasions both before and after the corrections had been applied. Before correction a slight decline in ventilatory capacity appeared both during and after the attack of purulence, but

T A B L E I I I

F.E.V.0.75 BEFORE, DURING, AND AFTER ATTACKS OF

\begin{tabular}{lc|c|c|c}
\multicolumn{4}{c}{ PURULENT SPUTUM } \\
\hline & & \multicolumn{3}{|c}{ F.E.V.0.75 (1.) } \\
\cline { 3 - 5 } & Before & During & After \\
\hline Uncorrected $\ldots$ & $\ldots$ & 1.78 & 1.76 & 1.76 \\
Corrected for time &. & 1.78 & 1.77 & 1.78 \\
\hline
\end{tabular}

the correction factor eliminates the latter and leaves a mean decline during the attack of only 0.01 litre. We concluded that an increase in sputum purulence in itself causes little acute effect on the ventilatory capacity of these men able to remain at work.

However, the mean decline in ventilatory capacity per year in those having attacks of purulent sputum was 0.111 ., compared with 0.0671 . in those without. Table IV gives this linear decline related to the presence of attacks of sputum purulence and to the type of pneumoconiosis. In both those with simple and with complicated pneumoconiosis the annual rate of fall in F.E.V. was greater when
T A B L E I V

DECLINE IN F.E.V. PER YEAR RELATED TO ATTACKS OF $\bar{Q}$ PURULENT SPUTUM AND PNEUMOCONIOSIS TYPE

\begin{tabular}{|c|c|c|c|c|c|}
\hline $\begin{array}{c}\text { Attacks } \\
\text { of } \\
\text { Purulent } \\
\text { Sputum }\end{array}$ & $\begin{array}{l}\text { Pneumo- } \\
\text { coniosis } \\
\text { Type }\end{array}$ & $\begin{array}{l}\text { No. } \\
\text { of } \\
\text { Men }\end{array}$ & $\begin{array}{c}\text { Mean } \\
\text { Age } \\
\text { (years) }\end{array}$ & F.E.V.0.75 & $\begin{array}{c}\text { Annual Fall } \\
\text { in F.E.V. (1.) }\end{array}$ \\
\hline Absent & $\begin{array}{l}\text { Simple } \\
\text { Complicated }\end{array}$ & $\begin{array}{r}4 \\
10\end{array}$ & $\begin{array}{l}52 \cdot 3 \\
56 \cdot 8\end{array}$ & $\begin{array}{l}2.15 \\
1.65\end{array}$ & $\left.\begin{array}{l}0.047 \\
0.074\end{array}\right\} 0.067^{1}$ \\
\hline Present & $\begin{array}{l}\text { Simple } \\
\text { Complicated }\end{array}$ & $\begin{array}{l}6 \\
8\end{array}$ & $\begin{array}{l}50 \cdot 5 \\
56 \cdot 4\end{array}$ & $\begin{array}{l}2.00 \\
1.61\end{array}$ & $\left.\begin{array}{l}0.087 \\
0.13\end{array}\right\} 0.11^{1}$ \\
\hline
\end{tabular}

${ }^{1}$ Difference significant $(0.01<P<0.02)$.

there were attacks of purulent sputum. Consider- $\omega$ ing simple and complicated pneumoconiosis to- $\dot{\omega}$ gether, the difference is statistically significant $\overrightarrow{0}$ $(0.02>P>0.01)$. The decline in F.E.V. appears 은 higher in complicated than in simple pneumo- coniosis in those both with and without attacks of $\subseteq$ purulent sputum. The mean annual fall in those with simple pneumoconiosis was $0.071 \mathrm{l}$., and with $\vec{\bullet}$ complicated pneumoconiosis 0.0991. , but the $\varnothing_{0}$ difference between them is statistically insignificant $(P>0 \cdot 2)$.

Figure 6 shows the incidence of the attacks of purulent sputum throughout the year. There is significant heterogeneity in incidence $(P<0.01)$, $\mathbb{D}$ with an increase in the winter months, but this can account for only a very small proportion of the difference in ventilatory capacity between winter and summer.

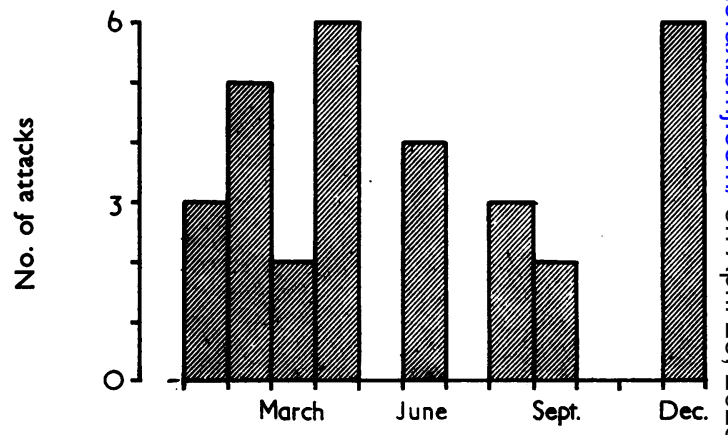

FIG. 6. Incidence of attacks of purulent sputum throughout $\omega$ the year.

There were no appreciable differences in smok- $\stackrel{\oplus}{-}$ ing habits in the two groups nor did we find a 0 relationship in individuals between the annual rate $\stackrel{\vec{D}}{\circ}$ of fall in F.E.V. and the smoking habit.

A comparison of Fig. 6 with Fig. 3B shows that $\frac{}{\stackrel{8}{\circ}}$ there is no relation between the distribution of the individual sine waves and that of these attacks of purulent sputum. 


\section{NORMAL SUBJECTS}

Variation in ventilatory capacity The group of 17 normal subjects was tested 13 times between October one year and December the next. There were altogether 19 missing observations, and these were estimated in such a way that the residual sum of squares in an ordinary analysis of variance was minimized, just as was done in the preliminary analysis of the group of ex-miners. This process of estimating the missing values makes no assumptions about the pattern of variation from month to month, but only that if those present have shown a change from the previous month, then those absent would have shown a similar change.

Figure 7 shows the average F.E.V. for each of the 13 test days. There is a marked rise from the minimum in November and December to a maximum in May and June, falling away again to the following winter.

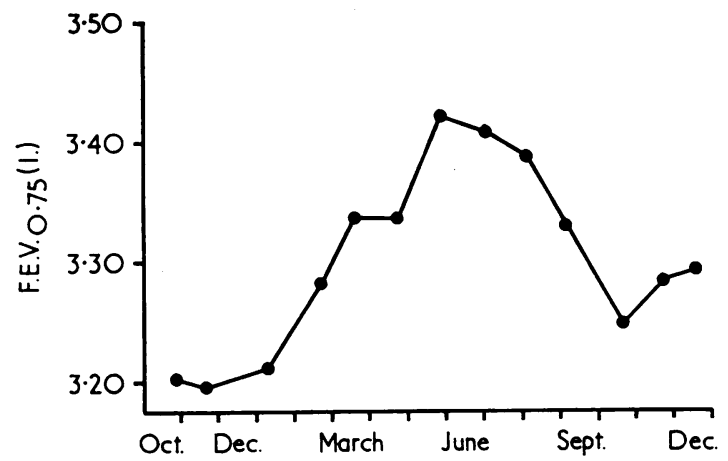

FIG. 7. The F.E.V..$_{\cdot 0 \cdot 75}$ of the normal subjects over 15 months.

As these observations extended over only 15 months, it would not have been appropriate to fit a sine wave, but these data are compatible with one having an amplitude peak to trough of about 0.101 ., compared with that of 0.0441 . in the sine wave of the disabled miners.

The group was of younger age than that of the ex-miners and contained sufficient subjects whose ventilatory capacity was still rising with growth to produce a small overall rise in F.E.V. from the first to the second winters, in contrast to the fall from year to year in the ex-miners. There was no evidence of a sex difference in either position or amplitude of the seasonal changes.

We also measured in this group the forced vital capacity which is shown in Figure 8 . This also increased with time but had a more irregular seasonal change, of which the maximum appeared to be in June and the minimum in November.

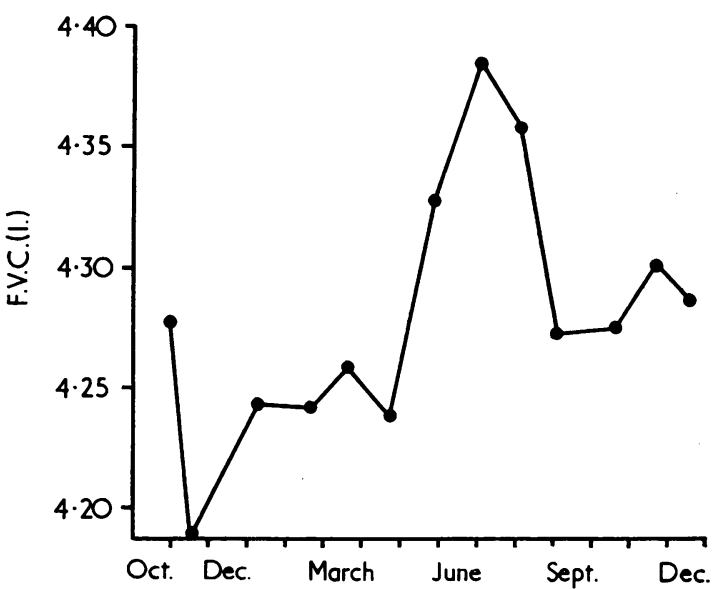

FIG. 8. The forced vital capacity of the normal subjects over 15 months.

\section{DISCUSSION}

An annual cycle has been demonstrated in the ventilatory capacity in the ex-mining and in the normal group of subjects. In the latter, the swing of $0.10 \mathrm{l}$. in the F.E.V. is quite large enough to be of practical importance in epidemiological or prospective studies as a cause of difference between one set of observations and another.

Several mechanisms for a cyclical change in respiratory function could be considered. The change might be an example of a 'biological rhythm'; many instances of these rhythms of various durations are known. For instance, circadian rhythms are found in adrenal cortical function (Bartter, Delea, and Halberg, 1962) and in renal function (Lobban, 1963). An annual sexual cycle occurs in many animals, and in some the pattern of waking and sleeping is profoundly changed with season. The rhythms are usually considered to represent an autonomous oscillation modified by a Zeitgeber of which the commonest is light (Aschoff, 1963). Thus Lobban and Tredre (1964) found that the cycles in renal function were related to solar time and seem to depend upon sight, being severely disturbed in the totally blind. Our findings are compatible with such a rhythm, the Zeitgeber perhaps being the environmental temperature, but more extended studies would be necessary to prove this.

A second mechanism could be a direct relation between the environment and the ventilatory capacity without the intervention of an intrinsic rhythm, and in this case one would expect a quantitative relationship between the severity of 
the environmental stimulus and the effect produced on the ventilatory capacity.

The present study is incomplete in that it was impossible to measure environmental changes as accurately or as frequently as was desirable, nor could all the factors possibly influencing ventilatory capacity be considered. In the factory group there was no evidence that a man's environment immediately before the test or during it influenced his results, but the cyclical components of drybulb temperature on the day of the test and ventilatory capacity were almost exactly in phase. However, the lack of correlation between the residuals about these sine waves does not support a causal relationship, although this is not excluded. There was no definite evidence of a relationship between the other environmental parameters and ventilatory capacity.

A similar relationship between external temperature and airways resistance (A.W.R.) has recently been reported by Spodnik, Cushman, Kerr, Blide, and Spicer (1966) in a study over eight months on 100 young men without symptoms. The highest values of A.W.R. were in February and March, but no clear cyclical change was detected. Their findings also showed that those with a history of asthma had a higher A.W.R. but were relatively insensitive to the environmental change. This is interesting in relation to our observation of a larger seasonal change in the F.E.V. of the normal than of the abnormal subjects.

It would also be plausible that a pair of factors, such as dry-bulb temperature and change in humidity, might together explain the change in ventilatory capacity. However, an extensive analysis using such pairs of factors has not shown that the ventilatory capacity variation is closely related to any particular pair.

The possibility that the cyclical change in F.E.V. is an artifact must be considered. The effect of changes in spirometer water temperature has been excluded. A possible but unlikely factor is the men's clothing. An increase in clothing worn below an unyielding waistcoat might reduce the ventilatory capacity in winter. Enquiries did not reveal any relation between ventilatory capacity and an increase in clothing. In general, clothing was increased in October or November, well before the minimum of ventilatory capacity.

It must be concluded that, within the limits of our ability to observe them, no environmental factors were directly responsible for the variation in F.E.V.

Finally, respiratory infection might be thought to produce a fall in ventilatory capacity in the winter months.
A change from mucoid to purulent sputum in the ex-miners produced no acute fall in ventilatory capacity, and in this our findings are in agreement with those of Angel, Fletcher, Hill, and Tinker (1965), in their London Transport and Post Office Savings Bank workers. Also the downward trend in ventilatory capacity preceded the main incidence of respiratory infections. Furthermore, the cyclical variation in F.E.V. was present in our normal subjects without respiratory infections, and it can be concluded that respiratory disease is unnecessary for the production of the seasonal changes. It is interesting that those subjects with attacks of purulent sputum in the winter showed a greater deterioration of ventilatory function with age than those in whom it remained mucoid. The reason is not clear; either the attacks of purulent sputum exert some chronic progressive effects on the respiratory system or those with a more rapidly declining ventilatory capacity are those most liable to minor respiratory infections.

The cause for the observed annual change in ventilatory capacity in those both with and without chest disease remains unproved, but perhaps the most likely mechanism is that of a biological rhythm linked to external environmental temperature. It would be interesting to know the relation of this rhythm to environment in other countries with different seasonal characteristics.

We are grateful to successive managers of the Junior Car Factory of the Austin Motor Co. Ltd. for assistance, and particularly to Mr. D. G. Selley, who read the instruments in the Stevenson screen in all weathers; to the late Dr. Idris Davies, the medical officer to the factory; to Dr. P. J. Lawther and members of the M.R.C. Air Pollution Research Unit for the air pollution measurements; to Dr. T. Ashcroft, who assessed purulence in the first year's sputum samples; and to Dr. J. C. Gilson, Director of the Pneumoconiosis Research Unit, for advice in the preparation of the paper.

Our thanks are also due to Miss M. B. Jones, the Sister in charge of the factory sick quarters, for much help ; to Mrs. Pamela Thomas for technical assistance; and to the subjects themselves, whose cooperation over the years made this study possible.

\section{REFERENCES}

Angel, J. H., Fletcher, C. M., Hill, I. D., and Tinker, C. M. (1965) Respiratory illness in factory and office workers. Brit. J. Dis. Chest, 59, 66

Aschoff, J. (1963). Comparative physiology: diurnal rhythms. Ann. Rev. Physiol., 25, 581.

Bartter, F. C., Delea, C. S., and Halberg, F. (1962). A map of blood and urinary changes related to circadian variations in adrena cortical function in normal subjects. Ann. N.Y. Acad. Sci., 98, 969

Fairbairn, A. S., Fletcher, C. M., Tinker, C. M., and Wood, C. H. (1962). A comparison of spirometric and peak expiratory flow measurements in men with and without chronic bronchitis Thorax, 17, 168 . 
Farr, W. (1885). Vital Statistics, Sanitary Institute, London.

Gilson, J. C., and Hugh-Jones, P. (1955). Lung function in coalworkers' pneumoconiosis. Medical Research Council, Special Report Series, No. 290.

Higgins, I. T. T., and Cochrane, A. L. (1961). Chronic respiratory disease in a random sample of men and women in the Rhondda Fach in 1958. Brit. J. industr. Med., 18, 93.

Holland, W. W. and Spicer, C. C. (1967). Influence of weather on respiratory disease. Biometeorology, 2, 30. Proc. 3rd International Biometeorological Congress. Pergamon Press.

Lobban, M. C. (1963). Human renal diurnal rhythms in an Arctic mining community. J. Physiol. (Lond.), 165, 75P.

- and Tredre, B. (1964). Renal diurnal rhythms in blind subjects. Ibid., 170, 29P.

McKerrow, C. B., McDermott, M., and Gilson, J. C. (1960). A spirometer for measuring the forced expiratory volume with a simple calibrating device. Lancet, 1, 149.

Millar, J. S., Nairn, J. R., Unkles, R. D., and McNeill, R. S. (1965). Cold air and ventilatory function. Brit. J. Dis. Chest, 59,23
Miller, D. L., and Jones, R. (1963). A study of techniques for the examination of sputum in a field survey of chronic bronchitis. Amer. Rev. resp. Dis., 88, 473 .

Morgan, D. C., Pasqual, R. S. H., and Ashford, J. R. (1964). Seasonal variations in the measurement of ventilatory capacity and in the answers of working coal miners to a respiratory symptoms questionary. Brit. J. prev. soc. Med., 18, 88.

Rogan, J. M., Ashford, J. R., Chapman, P. J., Duffield, D. P., Fay, J. W. J., and Rae, S. (1961). Pneumoconiosis and respiratory symptoms in miners at eight collieries. Brit. med. J., 1, 1337.

Rokaw, S. N., and Massey, F. (1962). Air pollution and chronic respiratory disease. Amer. Rev. resp. Dis., 86, 703.

Scottish Home and Health Department (1963). Report of a SubCommittee of the Standing Medical Advisory Committee. Bronchitis. H.M.S.O., Edinburgh.

Spodnik, M. J., Jr., Cushman, G. D., Kerr, D. H., Blide, R. W., and Spicer, W. S., Jr. (1966). Effects of environment on respiratory function. Arch. environm. Hlth, 13, 243.

Wells, R. E., Jr., Walker, J. E. C., and Hickler, R. B. (1960). Effects of cold air on respiratory airflow resistance in patients with respiratory-tract disease. New Engl. J. Med., 263, 268. 